معامل النضوج وأصل الصخور المصدرية لطبقات الصخور الرملية لتكوين انجانه في منطقة عقرة، شمالي العراق

$$
\begin{aligned}
& \text { محمد علي مال الله الراثدي } \\
& \text { قسم علوم التربة والمباه } \\
& \text { كلية الزراعة والغابات } \\
& \text { جامعة الموصل }
\end{aligned}
$$

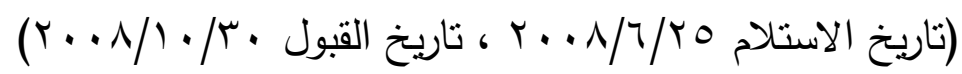

$$
\begin{aligned}
& \text { الملخص }
\end{aligned}
$$

دُرس مقطع تكوين انجانه في منطقة عقرة شمالي العراق، إذ تم اختيار 9 أنموذج من الصـخور

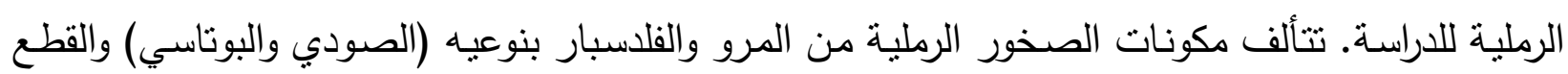

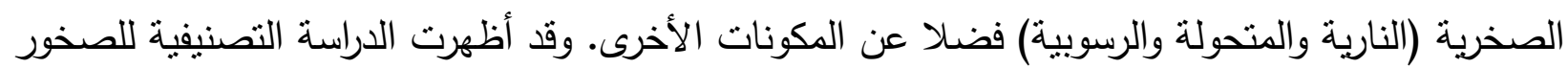
الرملية لمقطع الدراسة بأنها تقع ضمن حقل الليث ارينايت الفلدسباثي.

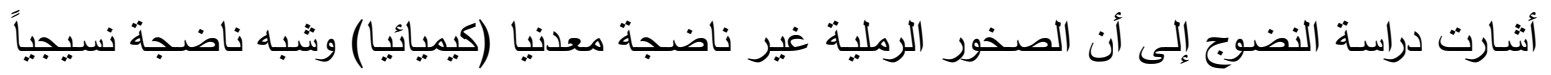

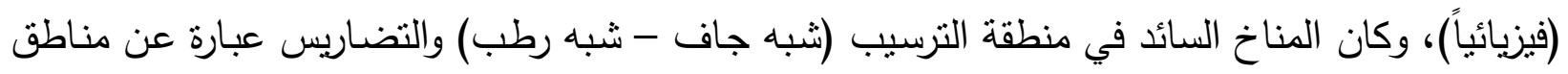

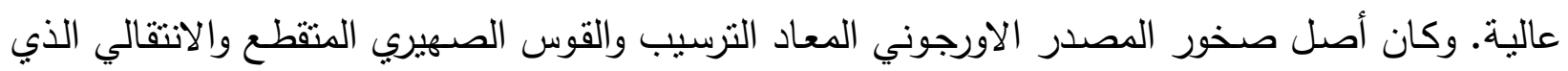

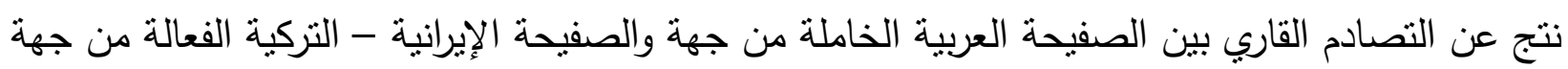
أخرى وكانت الصخور المصدرية صخور نارية ورسوبية ومتحولة.

\title{
Maturity Index and the Origin of the Source Rocks of Sandstones for Injana Formation in Aqra Region, Northern Iraq
}

\author{
Mohammed A. AL-Rashedi \\ Department of Soil and Water Sciences \\ College of Agriculture and Forestry \\ Mosul University
}

\begin{abstract}
The present study deals with the sandstones components of Injana Formation (Late Miocene) in Aqra area, northern Iraq. The Injana Formation consists of cyclic repetition of sandstones and claystones beds. Nineteen samples from sandstone beds were chosen for point counting and petrographic studies. The classification of these sandstone beds are feldspathic litharenite. Petrographic study shows that the sandstones consist of
\end{abstract}


mono and polycrystalline quartz, $\mathrm{K}-\mathrm{Na}$ feldspar, carbonate and other sedimentary rock fragments, igneous and metamorphic rock fragments and calcite cement. In addition finegrained clay matrix. The study marked mineralogical immature and physically submature sandstones.

These sediments were deposited under (semi arid-semi humid) climatic conditions. The origin of these sandstones were recycled orogen and dissected arc transition arc of the collision zone between the passive Arabian plate and the active Turkish-Iranian plates.

These events lead to sedimentary - tectonic intermeshing of the rocks on both plates which were uplifted as high terrains of igneous, sedimentary and metamorphic rocks, which are the source of Injana Formation sandstones.

\section{المقدمة}

يتتـاول البحث دراسـة الصـخور الرمليـة لتكوين انجانـه ( Injana Formation) بعدر المايوسين المتأخر (Bate Miocene) حسب (Bellen et al., 1959) في منطقة عقرة شمال العراق و ضمن نطاق

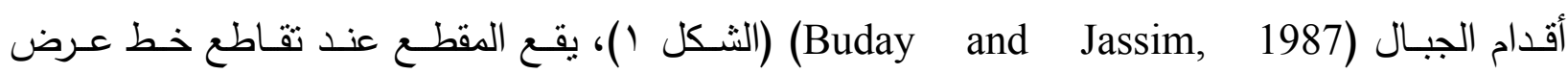

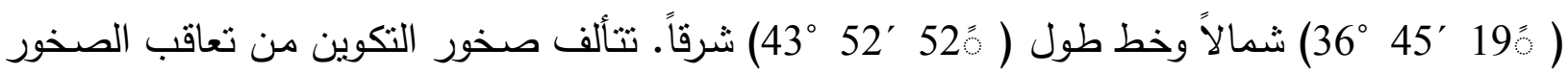

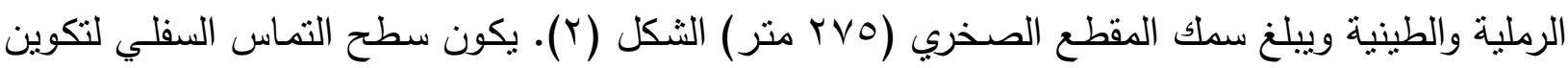

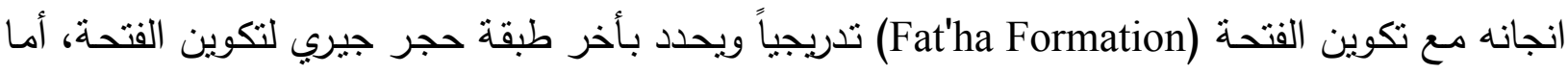

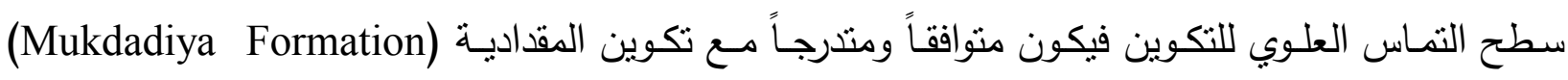
ويتحدد بظهور أول طبقة صخور رملية حصوية (Bellen et al., 1959).

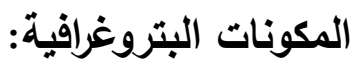

انتُب (9 (1) أنموذجا موزعة على طول مقطع تكوين انجانه في منطقة عقرة وذللك لحساب مكوناتها

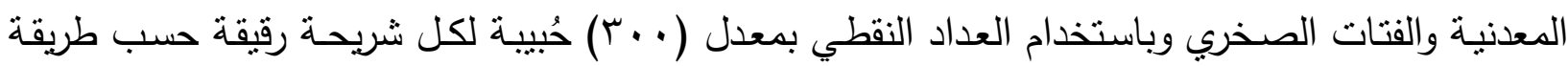
(Ingersoll et al., 1984) Gazzi-Dickinson الحمراء وفق طريقة (Friedman, 1959) للتميز بين معدني الكالسايت والدولومايت، وفيما يلي شرح موجز

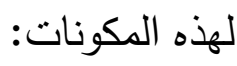

Mono and Polycrystalline ( المرو Quartz : وجدت حبيبات المرو بنوعيه الأحادي والمتعدد البلورات وكانت نسبة المرو الأحادي التبلور (21.46\%) اكبر من المرو متعدد البلورات (5uartz بسبب ضعف استقرار حبييات المرو متعدد البلورات خلال عملية النقل (Suttner et al., 1981) الجدول 


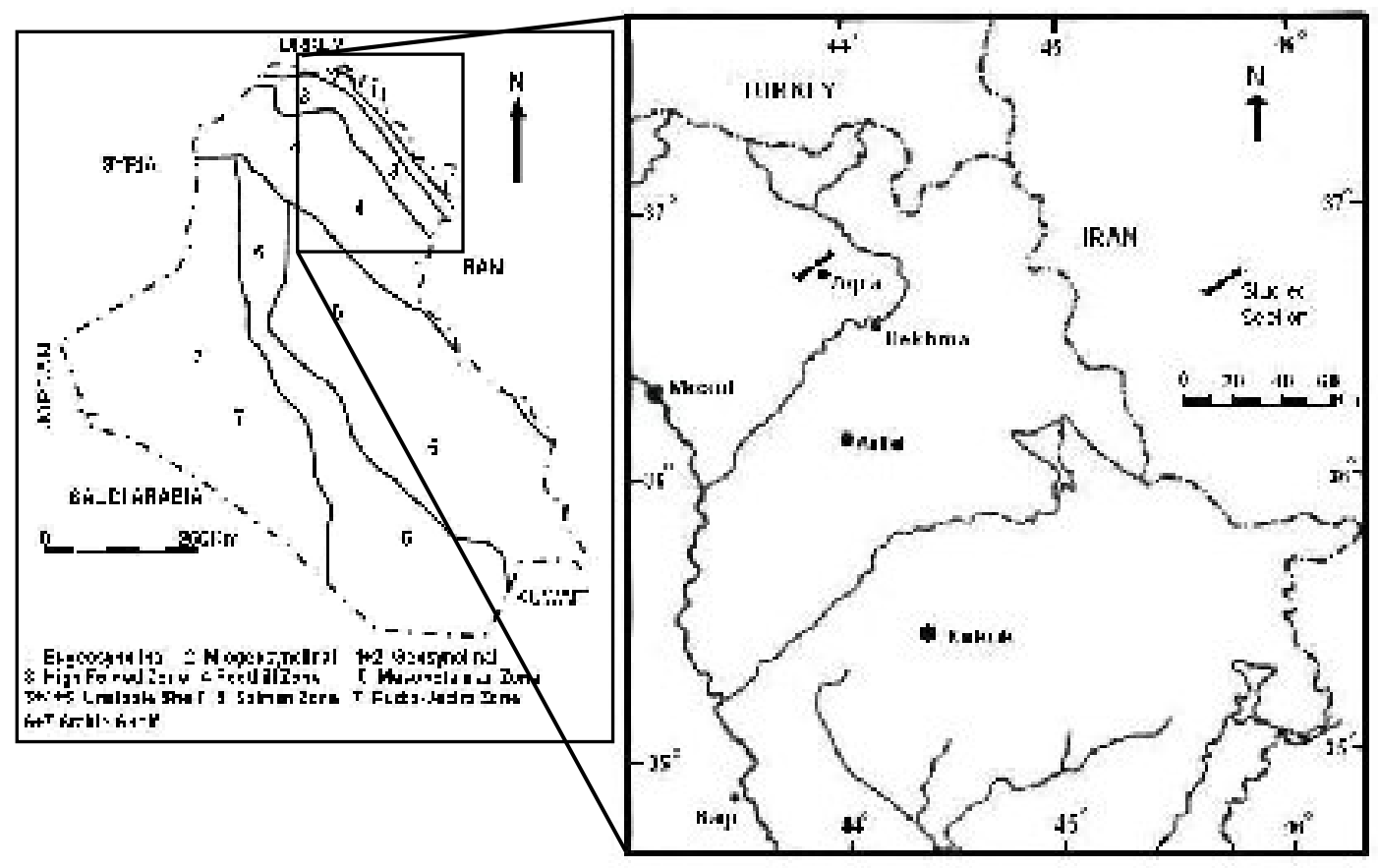

الثكل 1 : خارطة تبين موقع المقطع الصخري قيد الدراسة، وخارطة العراق التكتونية عن

.(Buday and Jassim, 1987)
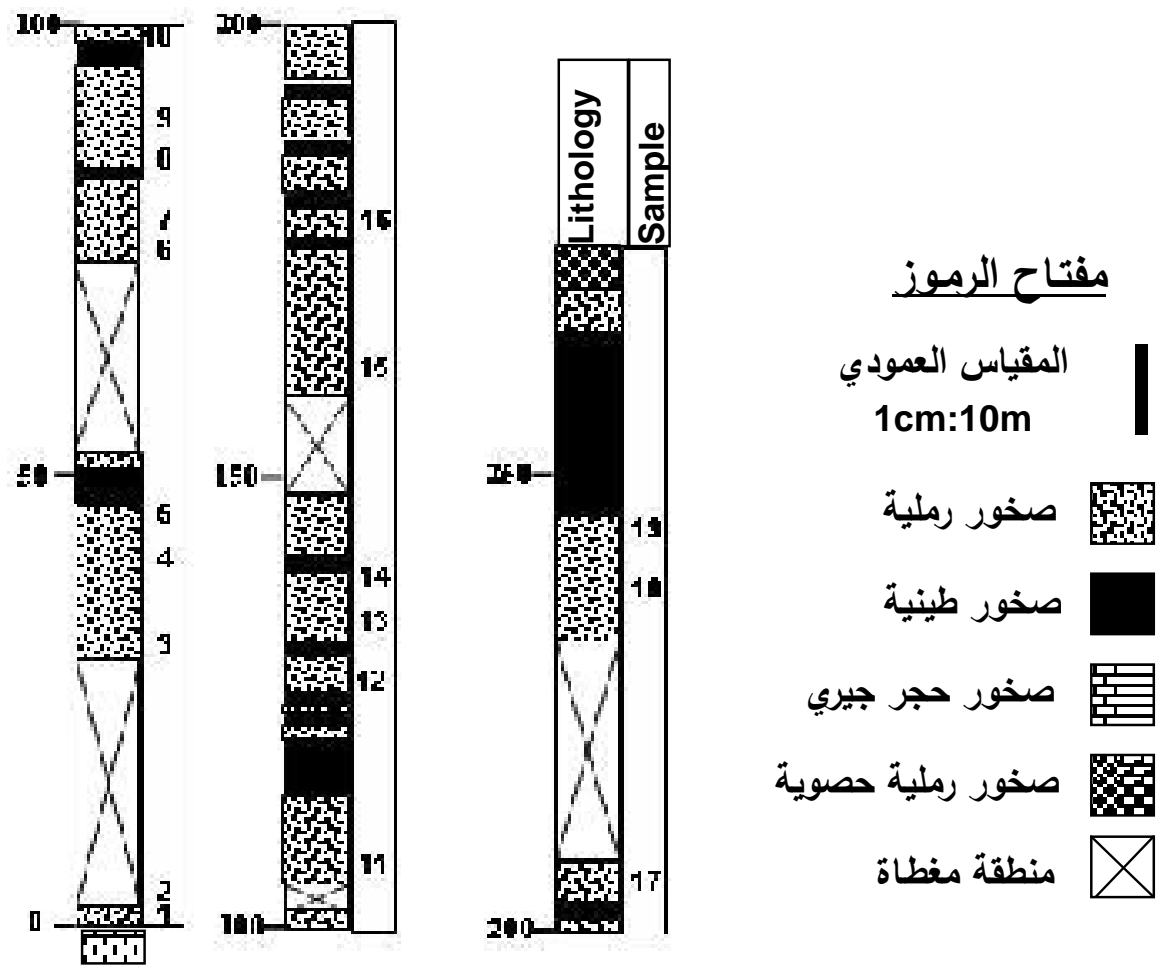

الشكل r: المقطع الصخري لتكوين انجانه ويظهر عليه مواقع النماذج الصخرية. 
محمد علي مال الله الراشدي 
تمتاز حبيبات المرو الأحادي التبلور بحجم حبيبي (ناعم - خشن) وذو شكل منساوي الأبعاد - متطاول

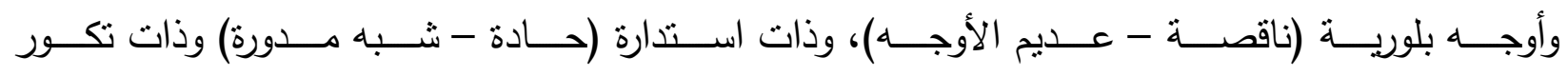
(واطـئ - متوسط) ويكون الانطفاء (مستقيم - متمـوج)، فضـلاً عن تواجد بعض المكتنفات من الزركون والروتايل واكاسيد الحديد، لوحة ( ( - (A ). يتكون المرو متعدد البلورات من أكثر من ثلاث بلورات وبأحجام مختلفة، وتفصل بين الحدود البلوربة حدود منحنية أو مسننة وذات انطفاء منموج لوحة ( - (B ).

القلاسبار Feldspar : يوجد الفلدسبار بنوعيه (البوتاسي والصودي) الاورثوكليز والبلاجيوكليز وكانت نسبة الاورثوكليز أعلى بصـورة عامـة (6.75\%) الجدول ( ()، وتمتاز حبيباته بأنها مغبرة وذات شكل لوحي ذو حواف (شبه حادة - مدورة) فضلاً عن الانطفاء المستقيم، في حين بظهر البلاجيوكليز بتؤمته المتعددة لوحة (C- (C)، كما لوحظ أن قسم منه قد تحلل إلى المعادن الطينية بصورة كلية أو جزئية، وبظهر هذا التحلل على طول مستوبات وسطوح الانفصام.

القطع الصخرية Rock Fragments: توجد القطع الصخرية الرسوبية بنسبة عالية في صخور التكوين (25.7\%) وتضم قطع الصخور الرسوبية (الكاربوناتية والطينية والرملية وقطع الصوان)، فضلاً عن القطع الصــرية المتحولـة والناريـة لوحسة ( (E, D - D)، كمـا يجـدر الإثـارة إلـى أن القطـع الصـخرية الرسـوبية الكاربونانية هي الغالبة على باقي أنواع القطع الصخرية وكانت بنسبة (11.99\%) الجدول ( ( ).

المكوذـــات الأذ ـ رى : تتباين نسب وجود المعادن الثقيلة ومعادن المايكا والكلورايت لوحة (F - F) في هذه الدراسة وهي بصورة عامة قليلة لكنها تستخدم كدليل على الأصل الصخري وفي فهم عملية التجوية. تنكون ألحشوة من المواد الطينية أو الغرينية والتي تمـلا الفراغات بين مكونات الصخور الرملية وتعد اغلب الحشوة في النماذج المدروسة من أصل ثانوي وذات أصل تحويري حسب (Dickinson, 1970). تتتوع المواد اللاحمة لتشمل السمنت الكاربوناتي والطيني واكاسبد الحديد والسيليكي، إذ لوحظ سيادة وتتوع السمنت الكاربوناتي والذي يكون على شكل سباري كالسايت يحيط بالحبيبات أو مالىئ للفراغات لوحة (F - أو بشكل قطع معزولة. فضـلاً عن وجود السـنت الطيني واكاسيد الحديد منرافقان مـع السـنت الكاربوناتي، أو يشكلان غلاف رقيق يحيط الحيبيات بلون احمر غامق أو بني. تم تصنيف الصـخور الرمليـة لتكوين انجانـة حسب (Folk, 1980)، وظهرت النتائج في حقل (Feldspathic litharenit) يشير إلى أن مكونات الصخور قد انتقلت مسافات قصيرة نسبياً وذلك لوجود معدن الفلدسبار ووفرة من القطع الصخرية، و يكثز تواجد هذه الرمال ضمن البيئة النهرية (البنا، بهو ()). 


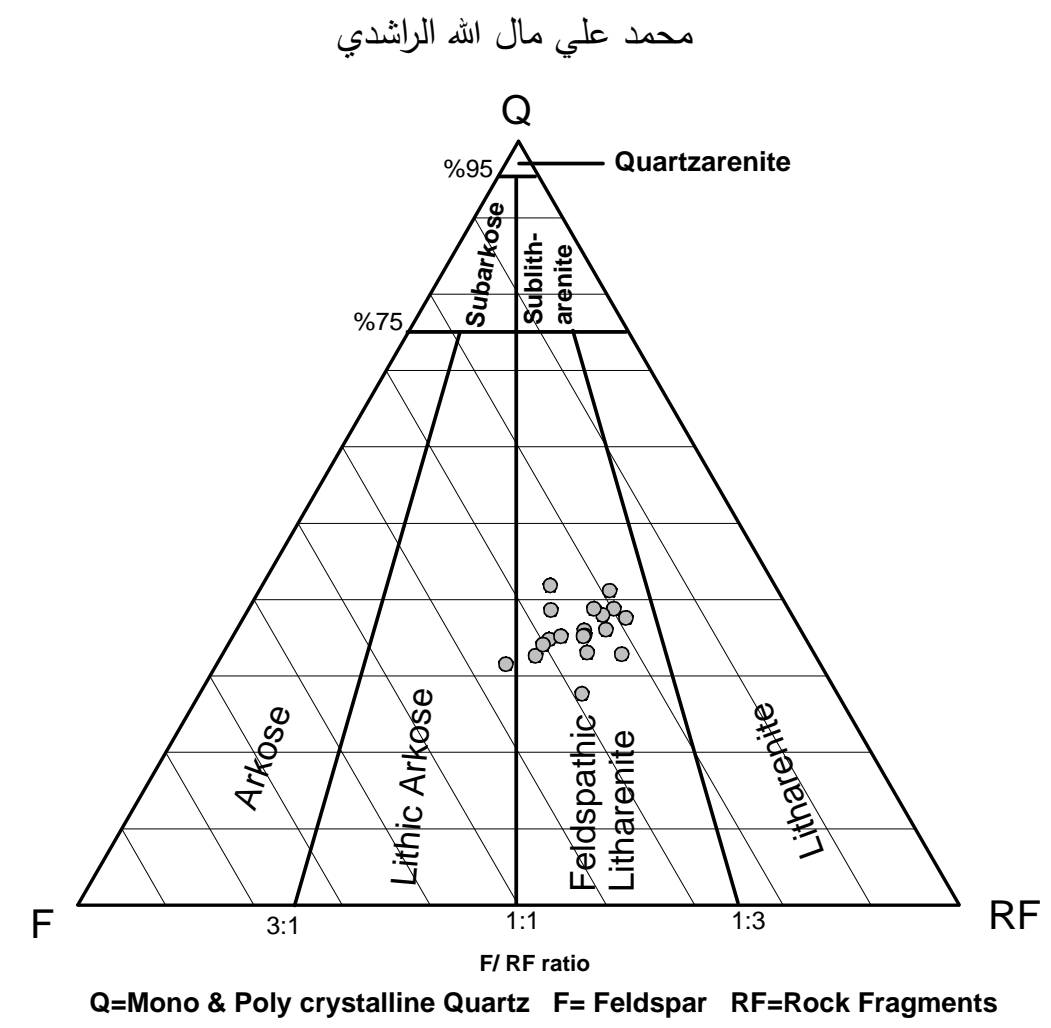

الشكل r : تصنيف الصخور الرملية لتكوين انجانه في مقطع الدراسة حسب (Folk, 1980).

\section{المناقثة}

أفرزت دراسة الصخور الرملية نتائج عن المحتويات المعدنية لهذه الصخور والتي استخدمت للتعرف على نضوج الصخور والمناخ القديم وكذلك أصل الصخور المصدرية، وفيما يلي مناقشة نتائج هذه الفقرات:

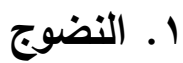

يستخدم معامل النضـوج في تسمية وتصنيف الصـخور الرملية، فيكون نضـوجها في اتجاهين كيميائياً وفيزيائياً، وبما أن الرواسب نتشكل من تجوية صخور مصدرية معقدة معدنياً تتعرض لعلية التجوية والنقل وبشكل متتاسب تتحلل وتقل المعادن غير الثابتة كيميائياً (الفلدسبار) وتزداد نسبة المعادن الثابتة كيميائياً (المرو). فيكون معامل النضوج الكيميائي (Chemical Maturity Index) للصخور الرملية هو نسبة تواجد المرو والقلدسبار في الصخرة (Selley, 1982). أمسا النضوج الفيزيائي فيصف التغيرات النسيجية (Texture changes) التي تمر بها الرواسب من فترة التجويـة حتى فترة الترسيب، وتشمل هذه التغيرات كلاً من الزيادة في درجة الفرز (Sorting) والاستدارة والانخفاض في محتوى راسب الأرضية أو الحشوة (Matrix) (Folk, 1951)، وبذلك يكون معامل النضوج الفيزيائي (Physical Maturity Index) هو نسبة الحبيبات (Grains) إلى رواسب . الأرضية وفي هذه الحالة يكون الطين هو راسب الأرضية الثائع. إذن يشكل محتوى الطين في الصخور الرملية مقياس عامل النضوج الفيزيائي أو النسيجي (Textural Maturity) (Selley, 1982)، وظهرت 
صخور الدراسة بان نسيجها شبه ناضـ (Submature) لوجود قليل من الطين الذي يمثل الأرضية

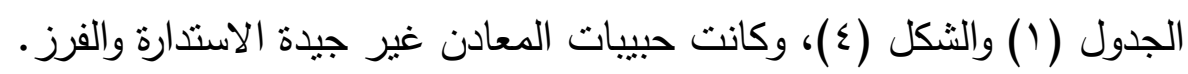

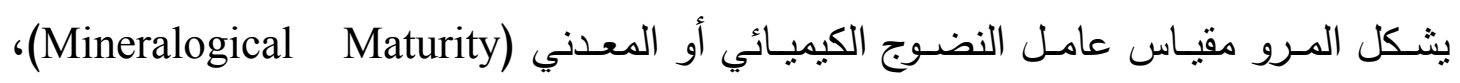

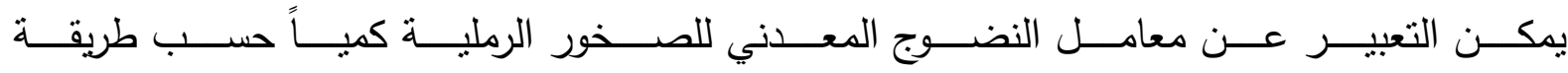
(McBride and Picard, 1987)

Mineralogical Maturity Index $(\mathrm{MMI})=\frac{\text { Quartz }+ \text { Chert }}{\text { Other grains }} * 100$

حيث أظهرت قيم النضوج المعدني بأن صخور التكوين غير ناضجة معدنياً الجدول (1). أنثار (Al-Juboury, 2001)

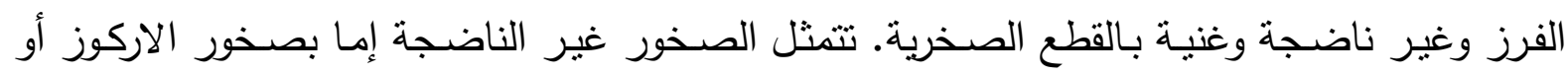

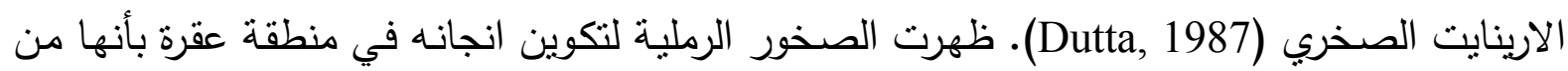
نوع الارينايت الصخري الفلدسباثي حسب (Folk, 1980) وان هذا النوع يمتاز بدرجة النضوجية المعدنية

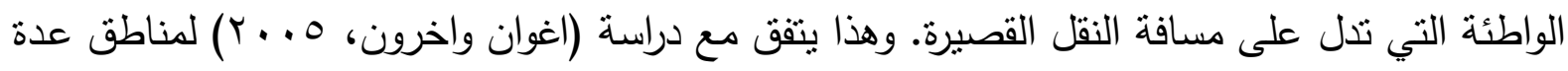

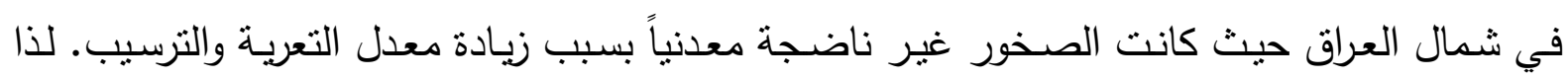

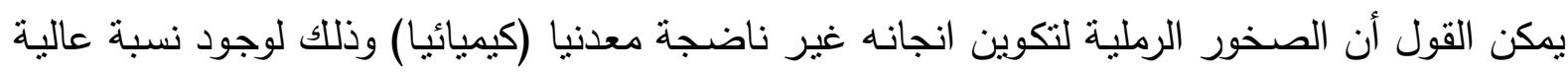

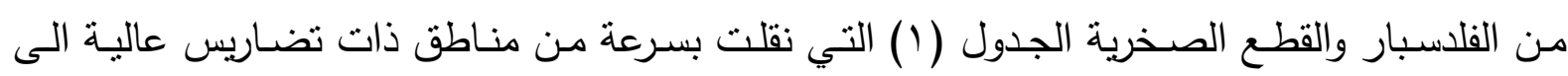
أماكن الترسيب أدى إلى الاحتفاظ بهذه النسبة العالية من الفلدسبار والقطع الصخرية، فضلاً عن كونها

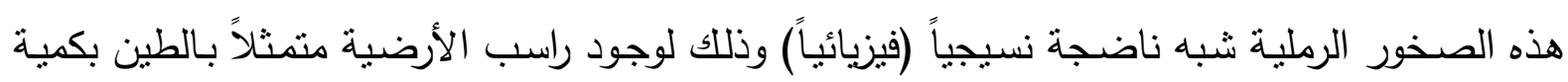
قلبلة (1.85\%) وكانت الاستخارة والفرز غير جيدة الثكل (4).

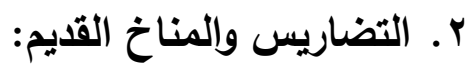

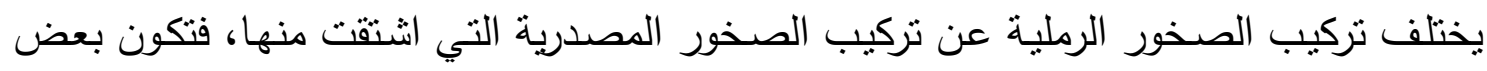

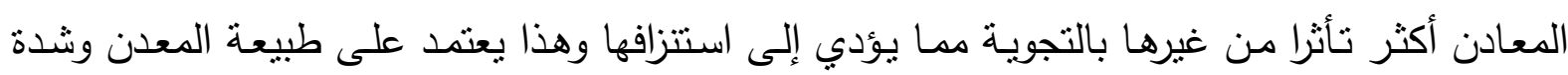

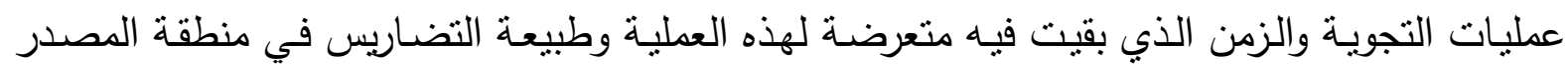
(Pettijohn, 1975)

من خـال الدراسـة البتروغرافيـة للصـور الرملية تبين أنها غنية بـالقطع الصخرية وخصوصـاً

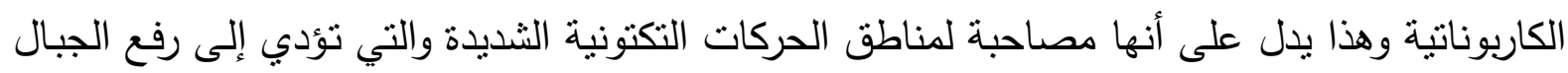
وتعريتها بسرعة في ظروف مناخية (ثبه جافة- شبه رطبة نسبياً)، حيث تغلب التعرية الميكانيكية. وبما

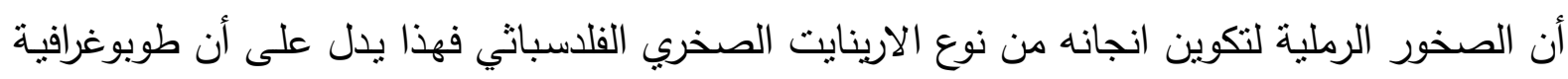


الصخور المصدرية كانت مناطق مرتفعة وفوالق زاحفة (Folk,1980). إن نسبة (المرو/الفلدسبار) تكون اكبر من واحد في صخور التكوين ونتير هذه النسبة إلى ظروف مناخية شبه رطبة في منطقة المصدر ، وكانت قيمة النضوج المعدني واطئة لصخور التكوين (49.85\%) وهي تدل على التعرية السريعة الناتجة برة

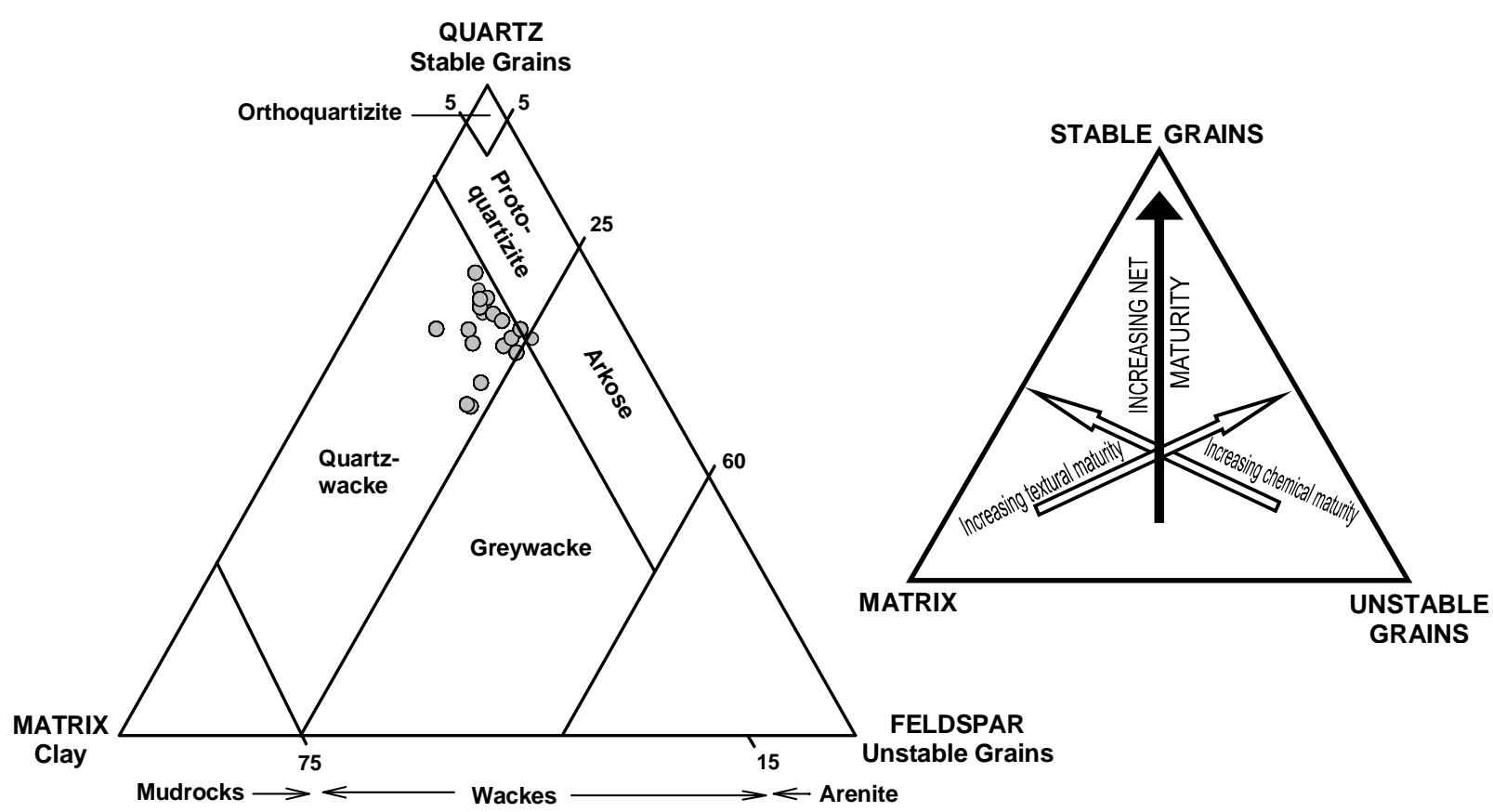

الثكل ؟ : تصنيف الصخور الرملية لتكوين انجانه باعتماد الطين كمؤشر على النضوج النسيجي (الفيزيائي) والفلدسبار على النضوج الكيميائي (المعدني) في مقطع الدراسة حسب (Selley, 1982).

لغرض معرفة دليل التجوية (Weathering index) (wi) فقد تم تمثيل نماذج الدراسة على العلاقة المقدمة من قبل (Suttner and Dutta, 1986) الثكل (B-5)، وأعطت هذه العلاقة الخلفية المناخية السائدة Von ) أثتاء ترسـيب تكوين انجانـه وهـي المنـاخ ( شبه الجـاف- شبه الرطب). كمـا استخدمـت علاقـة (Eynatten and Gaupp, 1999 الطوبوغرافي المرافق للترسيب الثكل (A-0)، وقد ظهرت قيمة دليل التجوية واطئة جداً (wi =0) والتي تدل

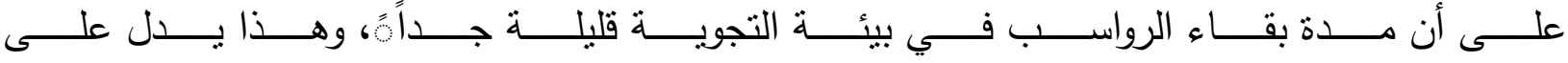

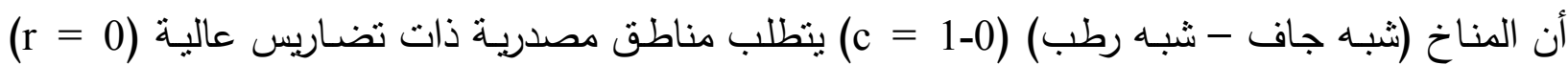
(الثكل 0-C) . وهذا يشير إلى أن الصـور الرملية لتكوين انجانه قد اشتقت مـن صـور ذات تضـاريس عالية ومناخ (شبه جاف - شبه رطب).

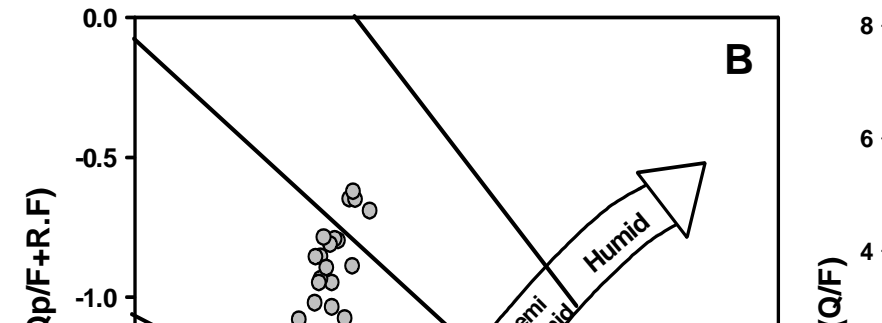

A 
معامل النضوج واصل الصخور المصدرية لطبقات الصخور

r. أصل الصخور المصدرية:

أثـار (Dickinson, 1985) إلى أن مكونـات الصنور الرمليـة تعكس بصـورة أوليـة الأوضـاع

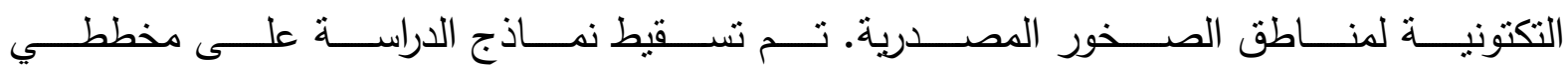

(Dickinson et al., 1983) مخطط (QmFLt) إلى نوع الصخور المصدرية السائد في وقت الترسيب، ظهرت النماذج في مخطط

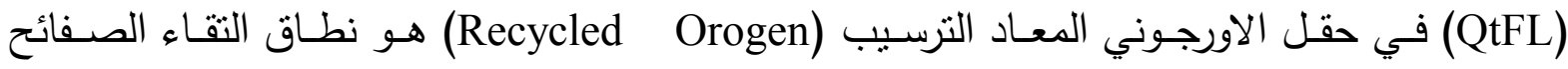

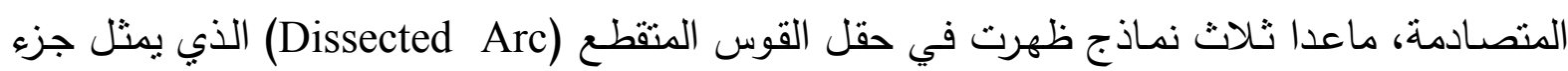


ثانوي من حقل القوس الصهيري (Magmatic Arc) الثكل (A-A). بينما ظهرت النماذج في مخطط (Dissected Arc) والقوس الانتقالي (QmFLt) (6-B)، وهذان الموقعان التكتونيان يمثلان نطاق أمام القوس (Dore Arc) وخلف القوس (Back Arc)

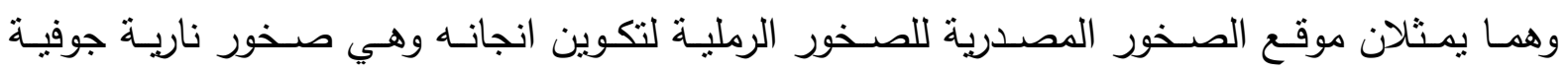

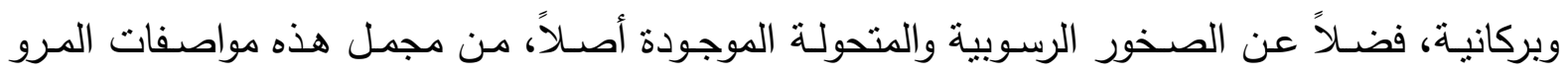

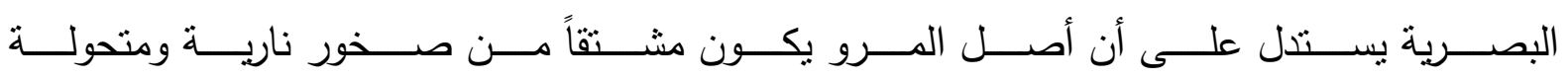

.(Folk, 1980)
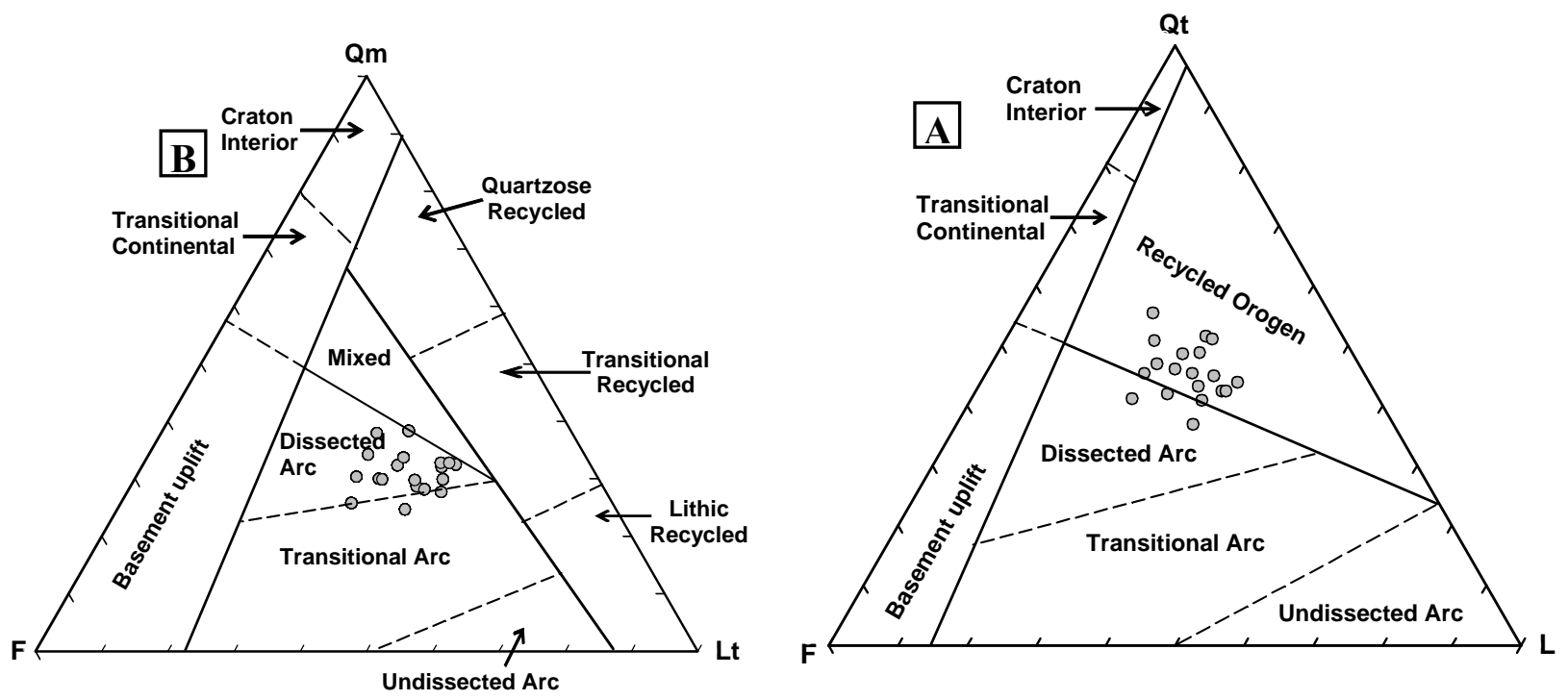

$\mathrm{Qt}=$ Total Quartz, $\mathrm{F}=$ Feldspar, $\mathrm{L}=$ Lithic Fragments, $\mathrm{Qm}=$ Monocrystalline Quartz, Lt $=$ Total Lithic Fragments .

الثنكل A-6 : مخطط (QtFL) يوضح نكتونية منطقة المصدر.

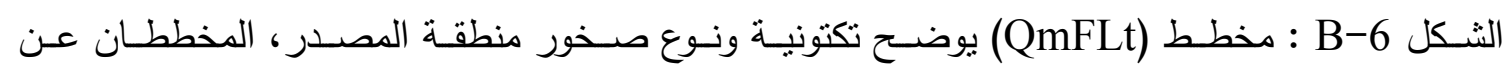
(Dickinson et al., 1983)

\section{الاستتناجات}

تتكون الصخور الرملية لتكوين انجانه من المكونات الآتية: المرو والقلدسبار ونسبة عالية من القطع

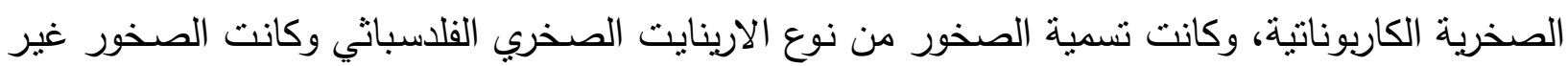

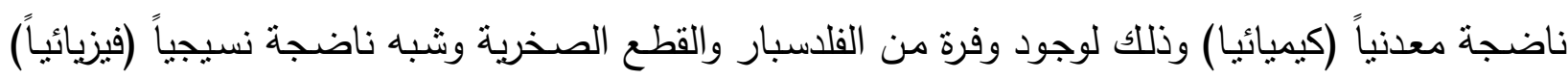

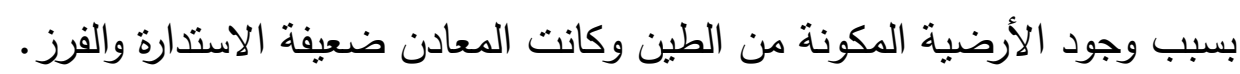
إن المناخ السائد في بيئة المصدر كان شبه جاف ورنه - شبه رطب، وبيئة صخور المصدر التكتونية

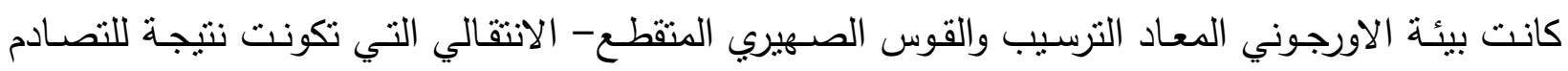




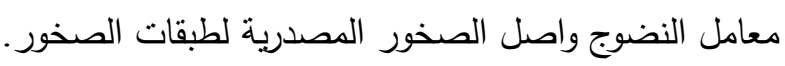

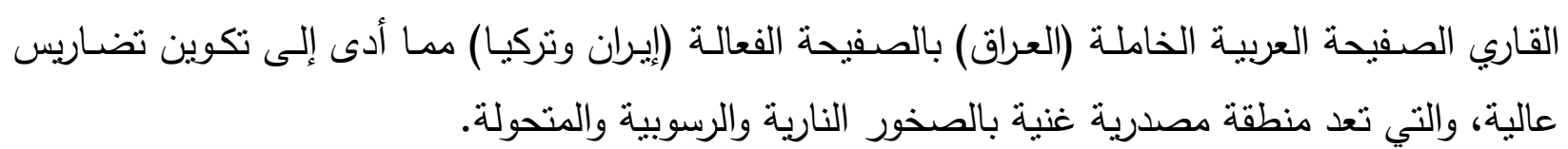

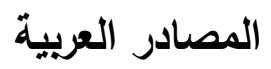

أغوان، ثامر عبد الرزاق والنقيب، سالم قاسم وال فتاح، أحمد نذير ، 0 . . r. النضوج المعدني وتأثير المناخ

والطوبوغرافيـة على الصـخور الرمليـة لتكوين انجانـه في منـاطق مختـارة مـن العـراق، مجلـة علـوم

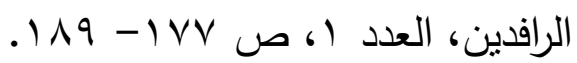

البنا، نبيل يوسف محمد، Y Y 1 ـ دراسة رسوبية لتكوين الفارس الأعلى في مناطق مختارة شمال العراق،

رسالة ماجستير غير منشورة، جامعة الموصل، كلية العلوم، IVV صفحة.

\section{المصادر الأجنبية}

AL-Juboury, A.I., 2001. Provenance and Paleogeography of Injana Formation in Iraq Based on Petrography and Heavy Mineral Distribution, Iraqi Jour. of Earth Sci., Vol.1, pp.36-51.

Bellen, R.C., Dunnington, H.V., Wetzel, R. and Morton, D.M., 1959. Lexique Stratigraphique International Asia, Fascicule, 10a, Iraq. Centeral National Deal Recherches Scientifique, Paris, 333p.

Buday, T. and Jassim, S., 1987. The Regional Geology of Iraq (Tectonism and Magmatism), D.G. of Geol. Sur. and Min. Inv., Baghdad, Iraq, 322p.

Dickinson W.R., 1970. Interpreting Detrital Modes of Graywacke and Arkose, Jour. Sedim. Petrol., Vol.40, pp.695-707.

Dickinson W.R., 1985. Interpreting Provenance Relations From Detrital Modes of Sdstones; In: Provenance of Arenites (ed.) G. G. Zuffa (Dordrecht: D. Reidel Pub. Co.), pp. 333-362.

Dickinson, W.R., Beard L.S., Brakenridge G.R., Erjavec J.L., Ferguson R.C., Inman K. F., Knepp R.A., Lindberg F.A. and Ryberg P.T., 1983. Provenance of North American Phanerozoic Sandstones in Relation to Tectonic Setting. Geol. Soc. Am. Bull., Vol.94, pp.222-235.

Dutta, P.K., 1987. The role of Variables in Controlling Sandstone Composition, In: Swenson, A.,(ed.). Professional Paper No.19, pp. 30-50.

Folk, R.L., 1951. Stages of Textural Maturity in Sedimentary Rocks; Jour. Sedim. Petrol., Vol.21, pp.127-130.

Folk, R.L., 1980. Petrology of Sedimentary Rocks, Hemphill Publishing Co., Austin, Texas, U.S.A, 182p.

Friedman, G.M., 1959. Identification of Carbonate Minerals by Staining Methods, Jour. Sedim. Petrol., Vol.29, pp.78-79.

Ingersoll, R.V., Bullard,T.F., Ford, R.L., Grimm, J.P., Pickle, J.D. and Sares, S.W., 1984. The Effect of Grain Size on Detrital Modes: A Test of the Gazzi-Dickinson PointCounting Method. Jour. Sedim. Petrol., Vol.54, pp. 103-116.

Le Pera, E., Arribas, J., Critelli, S. and Tortosa, A., 2001. The Effect of Source Rocks and Chemical Weathering on the Petrogenesis of Siliciclastic Sand From the Neto 
River(Calabria, Italy): Implication for Provenance Studies. Sedimentology, Vol.48, pp.357-378.

McBride, E.F. and Picard, M.D., 1987. Downstream Changes in Sand Composition, Roundness, and Gravel Size in a Short-headed, High-Gradient Stream, Northwestren Italy. Jour. Sedim. Petrol., Vol.57, pp.1018-1026.

Pettijhon, F.J., 1975. Sedimentary Rocks, ( ${ }^{\text {rd }}$ ed.). Harper and Row Publishers, NewYork, 628p.

Selley, R.C., 1982. An Introduction to Sedimentology, Academic Press INC. $2^{\text {nd }}$ ed., London, $417 \mathrm{p}$.

Suttner, L.J., Basu, A. and Mack, G.H., 1981. Climate and the Origin of Quartz Arenites. Jour. Sedim. Petrol., Vol.51, pp.1235-1246.

Suttner, L.J. and Dutta, P.K., 1986. Alluvial Sandstone Composition and Paleoclimate. 1. Framework Mineralogy; Jour. Sedim. Petrol., Vol.56, pp.329-345.

Von Eynatten, H. and Gaupp, R., 1999. Provenance of Cretaceous Synorogenic Sandstones in the Eastern Alps: Constraints From Framework Petrography, Heavy Mineral Analysis and Mineral Chemistry. Sedimentary Geology, Vol.124, pp.81-111. 


\section{معامل النضوج واصل الصخور المصدرية لطبقات الصخور}
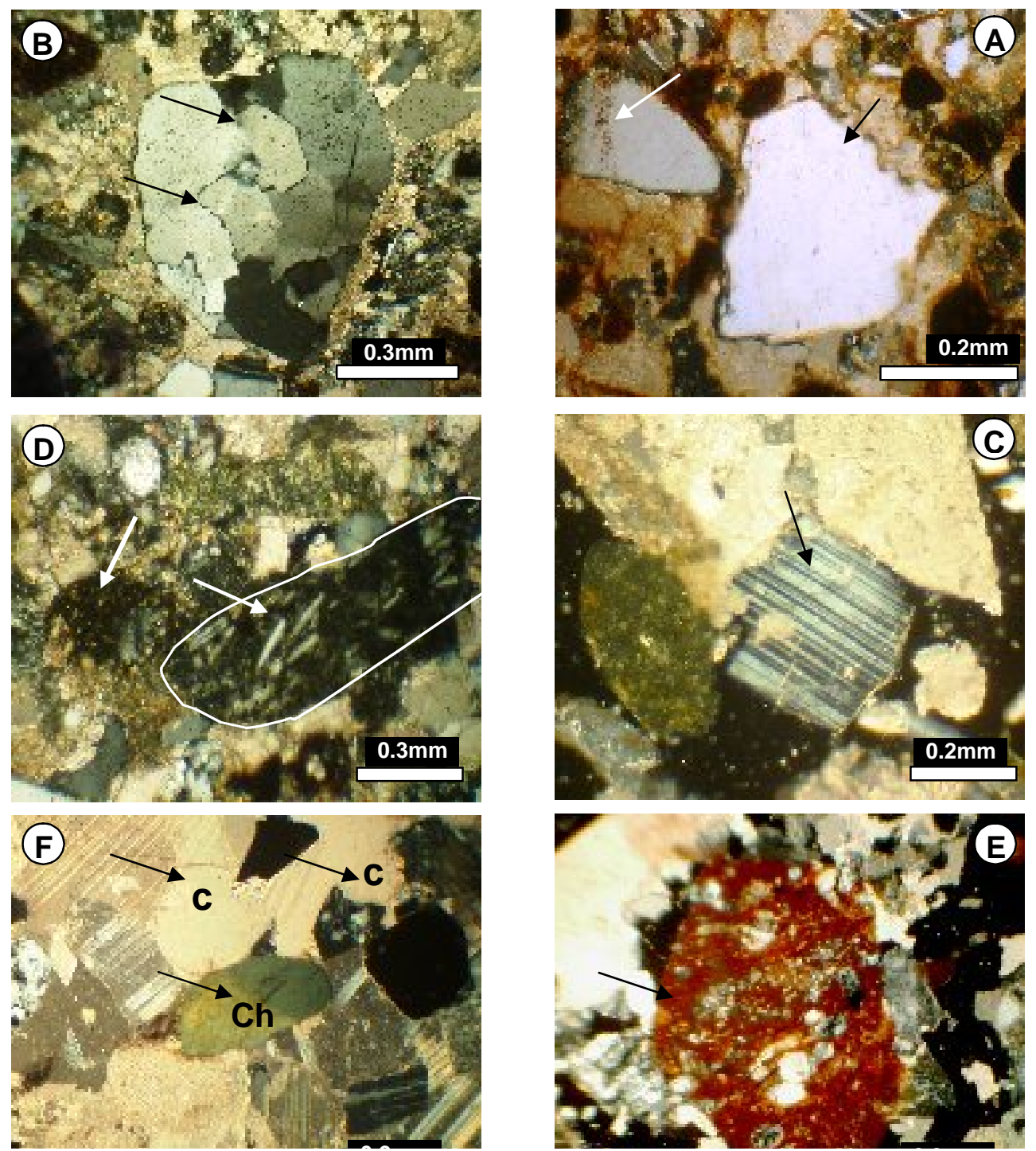

لوحة (1)

حبيبة مرو أحادي التبلور تظهر فيها مكتنفات، (B) حبيبة مرو متعدد البلورات وتظهر الحدود مسننة (A)

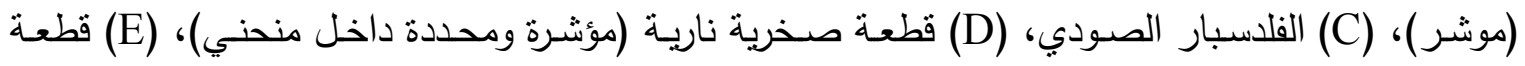

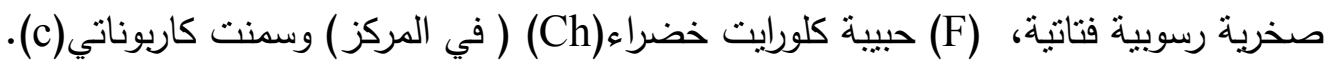

